\title{
Potencial de los recursos turísticos como oportunidad de recuperación económica en la región Apurímac, Perú, frente al Covid-19
}

\author{
Felipe Rafael Valle Díaz \\ fvalle@unajma.edu.pe \\ Universidad Nacional José María Arguedas \\ Andahuaylas-Perú \\ orcid.org/0000-0003-0855-9688
}

\section{RESUMEN}

El objetivo de la investigación fue: Describir, ilustrar, argumentar la contribución del potencial de recursos turísticos para la recuperación económica en comunidades campesinas de la región Apurímac, en respuesta al Covid 19. El propósito logrado: argumentar el tipo de actividad turística que sería el eje para iniciar la recuperación económica del sector turismo. El enfoque de investigación fue cualitativo, tipo estudio de caso, diseño narrativo. Las técnicas aplicadas fueron: captura de fotografía satelital, captura de fotográfica de lugares o sitios, análisis de documentos; experiencia del investigador, observación de hechos in situ. La muestra se caracterizó por la identificación de sistemas geomorfológicos, asociados con sitios arqueológicos. Como resultados tenemos: Existen barreras institucionales - administrativas, para formalizar el aprovechamiento de una zona o ruta ecoturística. La recuperación económica, es factible, por el poco monto de inversión, permitiendo el despegue de otras actividades directas e indirectas, nos referimos al Ecoturismo: hikking, trekking, acampar, andinismo, paisajismo, visita a sitios arqueológicos que se complementan con acampar y caminar por el kapacc ñan o camino inca. El aprovechamiento, se realiza bajo requisitos mínimos que se debe cumplir en la orientación turística para grupos pequeños, con capacidad motriz completa, además de los protocolos de seguridad, distanciamiento social.

Palabras clave: potencial, recurso turístico, covid 19, recuperación. 


\title{
Potential of the resources as an opportunity for economic recovery in the Apurimac region, Peru, in the face of Covid-19
}

\begin{abstract}
The objective of the research was: Describe, illustrate, argue the contribution of the potential of tourist resources for economic recovery in rural communities of the Apurímac region, in response to Covid 19. The purpose achieved: argue the type of tourist activity that would be the axis to start the economic recovery of the tourism sector. The research approach was qualitative, case study type, narrative design. The techniques applied were: capture of satellite photography, capture of photographs of places or sites, document analysis; Investigator experience, observation of facts in situ. The sample was characterized by the identification of geomorphological systems, associated with archaeological sites. As a result we have: There are institutional - administrative barriers to formalize the use of an ecotourism zone or route. Economic recovery is feasible, due to the small amount of investment, allowing the take-off of other direct and indirect activities, we refer to Ecotourism: hikking, trekking, camping, mountaineering, landscaping, visits to archaeological sites that are complemented with camping and walking by the kapacc nan or Inca trail. The use is carried out under minimum requirements that must be met in the tourist orientation for small groups, with full motor capacity, in addition to the security protocols, social distancing.
\end{abstract}

Key word: potential, tourist resource, covid 19, recovery.

Artículo recibido: 06. julio. 2020 Aceptado para publicación: 09. setiembre. 2020 Correspondencia: fvalle@unajma.edu.pe Conflictos de Interés: Ninguna que declarar 


\section{INTRODUCCIÓN}

A nivel mundial, la expansión global del virus COVID 19, ha hecho que los gobiernos de diversos países, establezcan estados de cuarentena para frenar la propagación de la pandemia. Graglia (2020) expuso bajo fuentes confiables que, desde el 09 de marzo del 2020, los países donde se había establecido y propagado el virus, eran del bloque de Asia menor y mayor, Estados Unidos, Italia, España, Francia, cuyos destinos turísticos fueron canceladas las reservas en 70\%. Para el 14 de marzo del 2020, el virus se estableció y expandió hacia América Latina, Oceanía, donde también se cancelaron las reservas a un 85\%. Al 24 de marzo del 2020, el virus llegó al continente africano y ocupó el 90\% del territorio de la tierra; para el mes de abril 2020, no había lugar que no escapara de la presencia del virus.

Graglia (2020) en base a las estadísticas de la Organización Mundial de Turismo, menciona que está crisis económica y del sector turismo llegará a tomar índices de recesión ocurridos en la última década del siglo $\mathrm{XX}$, tomando en consideración un escenario algo tolerable, no tan extremo.

Para abril del 2020, según la Organización Mundial de Turismo, un tercio de los viajeros han reprogramado viajes a partir de junio-septiembre, un $40 \%$ lo ha efectuado para el periodo octubre a diciembre y el 30\% restante para el 2021. Respecto a las últimas medidas de cuarentena, prohibiciones de viajes, cierres de fronteras; se estima que las llegadas de turistas internacionales en el mundo se reducirían entre un $20 \%$ al $30 \%$ en el 2020 (Turismo, 2020). Las estimaciones se aproximan a superar pérdidas por encima de los 450 millones de dólares, cuya crisis actual podría septuplicar la variación respecto a las cifras de la crisis del año 2009 (Turismo, 2020). Además de pérdidas por encima de 1,5 billones de dólares en exportaciones turísticas a nivel global.

Sin embargo el turismo como actividad económica-social-ambiental, tiene una capacidad de resiliencia, desde la crisis del 11 de septiembre del 2001 hasta la crisis financiera global del año 2009, experimentó una expansión de 675 a 892 millones de llegadas de turistas internacionales (Turismo, 2020), lo que demuestra la fortaleza y resiliencia del sector, cuya prueba es el crecimiento global del empleo en el sector turismo, que para América Latina entre el 2010 al 2018, creció desde el $21 \%$ al 37\%. Para el caso de Apurímac, (Turismo-Artesanía, 2019) hasta el año 2019 tenemos las siguientes estadísticas: 
Cuadro 1. Estadísticas de llegadas de visitantes al conjunto arqueológico Saywite, Santuario nacional de Ampay, Museo arqueológico antropológico de Apurímac al 2019.

\begin{tabular}{|c|c|c|c|c|c|}
\hline Recurso & $\mathbf{2 0 1 5}$ & $\mathbf{2 0 1 6}$ & $\mathbf{2 0 1 7}$ & $\mathbf{2 0 1 8}$ & $\mathbf{2 0 1 9}^{*}$ \\
\hline Saywite & 2562 & 3909 & 5213 & 6299 & 6480 \\
\hline Ampay & 3559 & 3809 & 3976 & 3585 & 3860 \\
\hline Museo & 1644 & 2446 & 6022 & 5441 & 5380 \\
\hline
\end{tabular}

*Estimaciones a diciembre 2019. Fuente: (Turismo-Artesanía, 2019). Elaboración propia.

Sin embargo, a pesar de la caída del sector turismo, existe una propuesta y directrices para tratar de recuperar este sector, (Turismo, Programa de asistencia técnica para la recuperación del turismo de la crisis de la Covid 19, 2020) ya tenemos certeza que existe una considerable cantidad de personas ligadas al sector turismo que han perdido el medio de sustento, además de agudizar la situación de pobreza en muchos países, todo el progreso alcanzado para llegar a cumplir con los Objetivos de Desarrollo Sostenible (ODS) está en retroceso. El turismo a nivel mundial ha demostrado una fuerte resiliencia y capacidad de adaptarse, innovar y recuperarse de las adversidades, prueba de ello es la crisis financiera del año 2009 y la crisis del SARS en el año 2003. Esta capacidad se centra en la versatilidad del sector y la adecuación de los operadores turísticos, asumiendo liderazgo en diversos ámbitos, como el restablecimiento de la confianza de los consumidores, la motivación al emprendimiento, mayor incremento de empleo a mujeres y jóvenes, sumado la innovación tecnológica en el marketing turístico. Ha propuesto a través del programa de asistencia técnica tres pilares (Turismo, 2020):

1. Recuperación económica, a partir de la medición de los impactos de la COVID 19 en el sector turismo,

2. Marketing y promoción, revisar, re direccionar las estrategias de promoción, identificar los mercados que pueden ayudar a acelerar la recuperación, diversificando productos, formulando recomendaciones y directrices en materia de precios y combinación de servicios.

3. Fortalecimiento institucional y resiliencia, tanto gobiernos y empresas deben adaptar sus servicios a las condiciones de trabajo posteriores al COVID 19, en materia de salud, seguridad y restablecimiento de la confianza de los consumidores, proponer gobernanza turística y alianzas público-privadas. 
Según entrevistas realizadas (Valle, y otros, 2020) a ex autoridades ligadas al cargo de la Dirección Regional de Comercio Exterior y Turismo Apurímac, 2019-2020, caso Lisbeth Salas Ccente y la Dirección Sub Regional de Comercio Exterior y Turismo Andahuaylas, casos: Enmanuel Gómez Choque 2018-2019 y Yanet Hurtado Oscco 2019-2020, existe una considerable cantidad de recursos turísticos, del tipo: natural, arqueológico, cultural, místico, religioso, que a la fecha no se cuenta con inventario, saneamiento físico-legal e inclusive los recursos turísticos con inventario, que a la fecha son aprovechados en convenio y soporte técnico con la Dirección Regional de Comercio Exterior y Turismo y/o Ministerio de Cultura, no cuentan con saneamiento físico-legal. Los recursos turísticos no inventariados, presentan un potencial, cuyo aprovechamiento haría posible que las comunidades campesinas, en el corto a mediano plazo, sintieran alivio frente a la situación económica negativa, generada por la cuarentena impuesta por el gobierno peruano ante la propagación del COVID 19. A agosto del 2020, el sector turismo en todos sus tipos está paralizado tanto a nivel nacional y regional en Perú, la reactivación económica es parcial e inclusive mínima, porque la propagación del virus COVID 19, no llega a un pico y descenso, en el territorio peruano, sigue expandiéndose, por ello superamos más de 28,000 fallecidos, 578,000 contagios confirmados, cifra oficial emitida por el Ministerio de Salud peruano.

Por ello, la pregunta general de la investigación se ciñó al contexto actual, en la forma: ¿Cómo podría el potencial de recursos turísticos contribuir a la recuperación económica en comunidades campesinas de la región Apurímac, en respuesta al Covid 19? Siendo el objetivo general de la investigación: Describir, ilustrar, argumentar la contribución del potencial de recursos turísticos para la recuperación económica en comunidades campesinas de la región Apurímac, en respuesta al Covid 19. La justificación se centra en que no hay escritos, argumentaciones, posiciones definidas tanto institucionales, científicas sobre cómo podría recuperarse el sector turismo, a nivel de provincia y región, cuál sería el tipo o sub tipo de actividad turística que sería el eje de enganche, para iniciar la recuperación del sector turismo, e inclusive, cómo este sector tan incipiente, podría tener la oportunidad de fortalecer y posicionar una nueva actividad económica en las provincias de la región Apurímac, sumado a ello la posibilidad de yuxtaponer otras actividades conexas al fortalecimiento del sector turismo. 


\section{MARCO TEÓRICO}

Respecto a la propiedad de la tierra donde se ubican los recursos turísticos, son territorios de comunidades campesinas, las cuales al amparo de la Ley 24656, y Ley 24657, los territorios comunales están protegidos, es decir inscritos en registros Públicos peruano, la función de las comunidades campesinas, protegen y preservan los recursos naturales, culturales y arqueológicos, por cuya función no reciben ningún pago o indemnización (Rural, 1999). Es notorio, su gobernanza y el deber de protección a los recursos turísticos.

Valle Díaz (2019) describe que presentan una fuerte cultura de protección a los recursos naturales y arqueológicos ubicados en su territorio comunal, no permiten el ingreso sin autorización, además que, para mantener costumbres, leyendas, anualmente realizan ceremonias o festivales en conmemoración de las etnias que se asentaron en los territorios donde actualmente siembran y cosechan. Asimismo, los acuerdos aprobados en asamblea comunal, son legitimados por todos los miembros de la comunidad, por ello las faenas comunales programadas al año, para el mantenimiento de senderos hacia los recursos turísticos, es primordial, necesario, además que refuerza el vínculo con sus costumbres y antepasados, es una prueba de su identidad (Valle Díaz, 2019).

El potencial turístico predominante es del tipo natural, la infraestructura y la planta de soporte están en estado de deterioro permanente, sumado que los habitantes de Machala, desconocen por completo la existencia de una considerable cantidad de recursos turísticos naturales, existe débil promoción turística, además de poco incentivo hacia la inversión privada (Ganchozo, 2018).

El Cantón de Paraíso cuenta con una considerable cantidad de atractivos turísticos, natural y cultural (Granados \& Morales, 2019); con debilidades en servicios para prolongar la permanencia de los turistas; la planta de soporte turística, formada por hospedajes y restaurantes, presentan limitaciones en diversificar la oferta de servicios, además de prácticas no adecuada con el medio ambiente: La actividad fuerte es el excursionismo que se desarrolla los fines de semana, donde la entrada es gratuita. Existe debilidades en la promoción turística, además que la municipalidad no cuenta con un plan de desarrollo turístico. 
El potencial de recursos turísticos en el cantón de Mocache, es impresionante, cantidad considerable, no cuentan con saneamiento documentario, por ello no se puede realizar promoción, existe confusión, disfunción organizacional en funcionarios municipales, porque desconocen el registro o inventario de los recursos turísticos, sumado que no existe información de los recursos turísticos actualizada, están en abandono (Tumbaco, 2019).

En Manta cuenta con una cadena hotelera de cinco estrellas, pero solo representan el $15 \%$ del sector hotelero de Ecuador, el resto son empresas familiares, los cuales no presentan un crecimiento y desarrollo satisfactoria de sus servicios y situación económicafinanciera desde hace años, igual es el caso de restaurantes, agencias de viaje, donde deben implementar nuevas estrategias, convertir el modelo de negocio actual, priorizar los canales de distribución-promoción (Félix \& García, 2020). Es importante que la recuperación del sector turismo se centre en la intervención del cooperativismo y la colaboración público-privada como estrategia para la comercialización turística, formalización de emprendimientos, capacitación y asistencia técnica, sumado a los estudios de la academia.

Bajo un modelo de correlación lineal, cuyas variables fueron variación anual del producto bruto interno de la región Cusco, razón de la inversión en el sector turismo entre la inversión total ejecutada, la tasa de interés efectiva anual real en moneda nacional, variación anual o crecimiento del número de arribos, la variación anual del gasto promedio realizado por el turista y la razón de los ingresos por turismo entre el valor de las exportaciones nacionales, obtuvieron como resultado, que en el periodo del $2000 \mathrm{al}$ 2015, si hubo crecimiento positivo, además modelaron para la región Cusco, que una variación del $1 \%$ de la razón de inversión en turismo sobre la inversión total, el PBI del Cusco variará en $2.3 \%$ y si la razón varía en 10\%, el PBI de Cusco variaría hasta un 30\% (Gonzales \& Huanca, 2018).

Aguilar y Sáenz (2019) arribaron que el potencial de los recursos turísticos en el municipio de Mariquita, son sus atractivos turísticos ligados a lo cultural e histórico, las cuales se soportan en el calendario anual de actividades turísticas, sumado a la riqueza natural, además que el uso de estos recursos, sostienen la oferta turística en el municipio de Mariquita. 
el tipo de investigación es básica, diseño descriptivo, describe un inventario de los recursos turísticos naturales de los seis lagos que forman la cuenca del río Chumbao (Valle, Huamán, \& Salas, 2019). La propuesta de la zona ecoturística se ciñe a los atributos y condiciones que existen, contemplando un plan con tres fases específicas. Se establecieron la cantidad mínima de atención de grupos medios de 10 personas máximo, además de tarifas de ingreso.

La investigación tuvo como propósito describir e ilustrar el aprovechamiento de la zona ecoturística Orccopi Kunaman Suitoccocha, la cual contiene una diversidad de paisajes, sostenidos en montañas, lagos, depresiones, quebradas, además de infraestructura piscícola (truchas) además de un camino inca o kapacc ñan. La accesibilidad es regular a buena, tanto la externa hacia el recurso turístico, como al interior, senderos en el recurso turístico, se suma áreas libres para acampar (Valle, Salazar, \& Ripa, Aprovechamiento de la zona ecoturística Orccopi Kunaman Suitoccocha, distrito José María Arguedas, Apurímac, Perú, 2020). El plan de aprovechamiento, presenta dos fases específicas, la primera intervención con mínima inversión y la segunda con una inversión considerable por la implantación forestal.

Un recurso turístico es todo elemento natural o actividad humana, que puede generar un desplazamiento por motivos de ocio, distracción, placer. Un producto turístico se forma por: recurso turístico, infraestructura, equipamiento y servicios. Cuando se realiza un inventario se busca datos respecto a: descripción, accesibilidad, infraestructura, actividades complementarias, grado de uso, tipo, categoría, ubicación, localización (Marín, 2012). 


\section{METODOLOGÍA}

La metodología de la investigación (Hernández, Fernández, \& Baptista, 2014) se apoyó en el enfoque cualitativo, tipo estudio de caso, diseño narrativo, método narrativo y análisis de entrevistas. Las técnicas usadas revisión documentaria, captura fotográfica satelital, experiencia del investigador, observación in situ. Los instrumentos aplicados fueron: fotografía satelital, fotografía de lugares o sitios, investigaciones y/o publicaciones de artículos relacionados al potencial turístico de ambas provincias y región; narración del investigador, observación de hechos in situ. La muestra, (Chancos, 2019) se caracterizó por la identificación de sistemas geomorfológicos, asociados con sitios arqueológicos.

"El inventario nacional de recursos turísticos, es una herramienta de gestión que permite recabar información real, ordenada y sistemática de los recursos turísticos e identifica el potencial turístico del país" (Turismo, 2018, p. 14). Para el trabajo de investigación, solo se toma la fase I, respecto a la categorización, que significa: "recopilar información, proceso que ordena los datos y clasificar los lugares, objetos, acontecimientos y otros de interés de los recursos turísticos del país, región o área determinada” (p. 16) Cualquier verificación, contrastación de fuentes secundarias con la realidad, se hace in situ, poniéndose énfasis si existe vulneración, destrucción, huaqueo, de las instalaciones turísticas del recurso turístico, sumado la importancia de la accesibilidad al recurso turístico, la cual no debe ser restringida, además es importante el estado de conservación, porque cuando se ubica, identifica un estado de destrucción o pérdida, no deben ser registrados, porque no se pueden recuperar (p. 17).

\section{RESULTADOS}

Las provincias de Andahuaylas, Abancay, Chincheros, hechas las revisiones documentales, el territorio provincial es ocupada la superficie en un $80 \%$ por los dominios y propiedad comunal, es decir la propiedad es de régimen comunitario; no existe propiedad privada al interior de un territorio comunal, asimismo los recursos turísticos en sus tipos: naturales, arqueológicos, culturales, vivenciales, están en su gran mayoría contenidos al interior del territorio comunal. Los recursos turísticos están ubicados, delimitados, por las organizaciones comunales; existe normas de comportamiento 
internas, que limitan el deterioro, hurto, aprovechamiento indebido del recurso turístico por factor humano. Son guardianes, vigilan que no se expanda el huaqueo, dañen el recurso turístico. Los recursos turísticos, a la fecha están conservados por las condiciones geográficas de topografía y avance de la naturaleza. Por lo general existen a la par recursos turísticos asociados tales como: arqueológicos-naturales, históricos-vivenciales. Una considerable cantidad de recursos turísticos, sobre todo arqueológicos, presentan una accesibilidad media a mayor, de traslado hacia el recurso turístico y senderismo al interior del recurso turístico. Los recursos turísticos, la mayoría cuentan con fichas de inventario, desactualizadas.

Cabe resaltar que, en las provincias indicadas donde se ubica las plantas de soporte, se cuenta con una poca cantidad de recursos turísticos, categorizados, jerarquizados según la metodología del Ministerio de Comercio Exterior y Turismo, competencia del Vice ministerio de Turismo, además fortalecidos a nivel de destino turístico, dentro de ellos encontramos en Andahuaylas: Complejo Arqueológico de Sóndor, Lago de Pacucha, Petroglifos de Lliupapuquio, Iglesia San Pedro, Iglesia Santiago Apóstol, Iglesia San Jerónimo, Bosque de piedras, Pankula, Pirámide trunca, todos ellos no cuentan con reportes estadísticos, sumado a debilidad en infraestructura turística en el propio recurso turístico. Además de la inexistencia de administración para el mantenimiento del recurso turístico, lo cual evidencia deterioro en avance.

En Abancay encontramos: Piedra Sayhuite, Templo Abancay, Santuario Ampay, Museo antropológico, los cuales cuentan con estadísticas, además de infraestructura de soporte mínima en el recurso turístico, la plataforma Turismo in ligada a Prom Perú, dependiente del Ministerio de Comercio Exterior y Turismo Perú, brinda información de los tres primeros destinos turísticos. En la provincia de Chincheros, el recurso turístico, desarrollado con limitaciones, cuyo arribo o temporada se masifica la visita de turistas es en septiembre de cada año, nos referimos a la Iglesia de la Virgen de Cocharcas, cuenta con ficha de inventario, con planta de soporte con condiciones limitadas, para el caso de pernoctación, transporte permanente, el paisaje es único.

En contraste existe, un sinfín de recursos turísticos, cantidad considerable de ellos inventariados y otros no, y cuyas fichas de inventario están desactualizadas, además que no se puede realizar ningún trabajo de mejora, recuperación porque no existe el 
saneamiento físico-legal de la propiedad del recurso turístico, de tal forma que la inversión que se inyecte permita generar condiciones para un aprovechamiento racional, amigable con el medio ambiente; en sí están débilmente trabajados como destino turístico y otros sin trabajo alguno, para Andahuaylas, identificaremos al recurso turístico, su ubicación en la comunidad campesina y distrito, tenemos:

1) Complejo Achanchicc, contenido en las comunidades campesinas de Uchuhuancaray, Bellavista del distrito de Talavera.

2) Complejo de Auquimarca y Centro Ceremonial Apu Puyca, ambos contenidos en la comunidad campesina y distrito Pomacocha.

3) Pabellones contenidos en la comunidad campesina y distrito Pampachiri.

4) Cuevas de Ccasiachi, contenidos en la comunidad campesina de Toracca y distrito de Turpo.

5) Cuevas de Lliusinayocc, contenidos en la parcialidad de predios privados de Ampi, distrito de Pacucha.

6) Complejo arqueológico Chontalla, contenidos en la comunidad campesina y distrito Pampachiri.

7) Sitio arqueológico de Naupallaqta y cataratas, contenidos en la comunidad campesina y distrito Chiara,

8) Sitio místico-religioso de Waku quri, contenidos en la parcialidad privada de Pulluri, distrito de Kaquiabamba.

9) Sitio arqueológico de Llaqtapata e Incañan, contenidos en la comunidad campesina de Ccerabamba Andina y la parcialidad de privados Pacchani, distrito de Pacobamba.

10) Chullpas de Ayapata y Museo de sitio, contenidos en la comunidad campesina de Natividad-Ataccara, distrito de Huancaray

11) Complejo natural del Apu Timani, contenidos en la parcialidad privada de Anyaniso, del distrito de Kaquiabamba. 
12) Bosque Uywari, contenidos en la comunidad campesina de Villa Esperanza Cotahuacho, del distrito de Pacucha.

13) Lagos de Lliupapuquio, contenidos en la comunidad campesina de Lliupapuquio, del distrito de San Jerónimo. Ilustraremos, describiremos algunos de los citados.

14) Lagos de Tintay, contenidos en la comunidad campesina de Tintay, del distrito de Kishuará.

15) Lagos de Suitoccocha, contenidos en la comunidad campesina de Huancabamba-Checchce-Huaraccopata, del distrito de José María Arguedas. Ilustraremos, describiremos algunos de los citados.

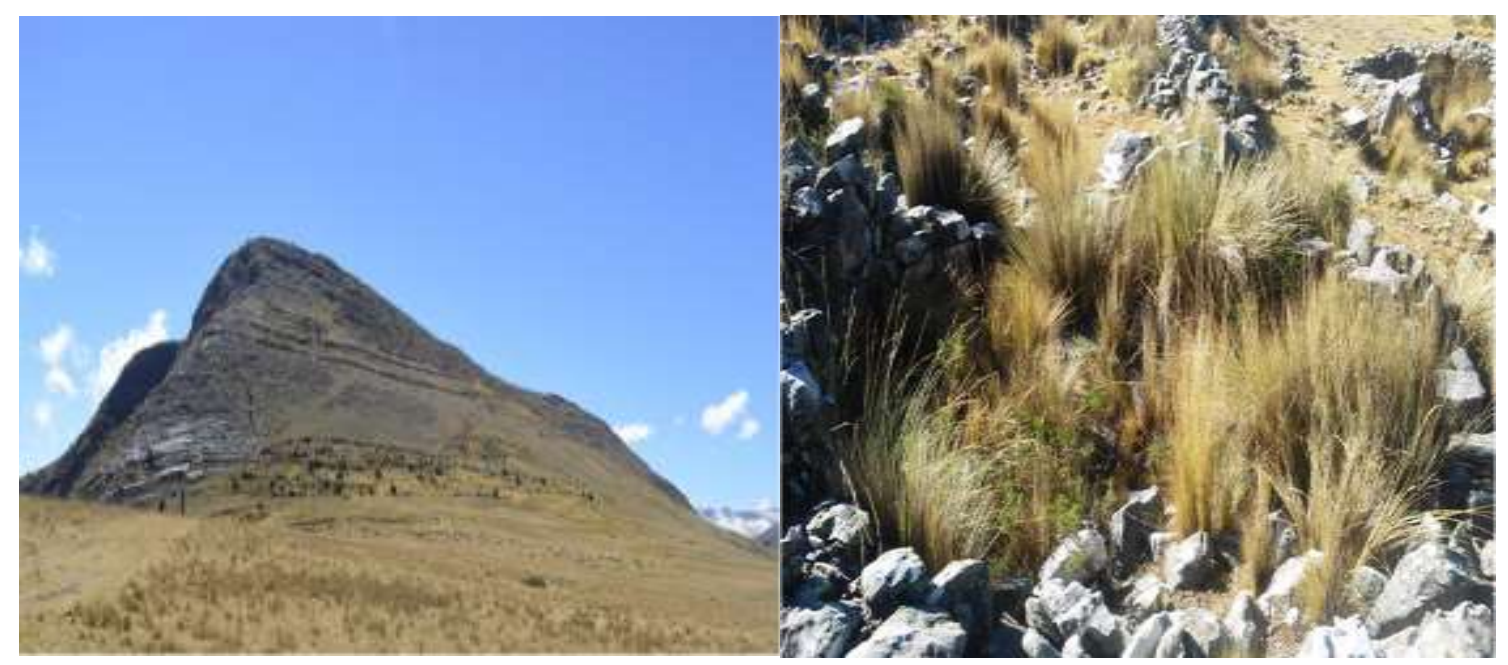

Fuente: Recurso arqueológico de Auquimarca. 24.10.2019. Recurso turístico con ficha de inventario desactualizada, abandonada su recuperación. Protegido por la Comunidad Campesina y distrito de Pomacocha. Cuenta con tres niveles de protección mediante andenerías, recintos: ceremonial, viviendas ovaladas, plazas mayores en la cumbre a la espalda o sentido cardinal norte, parte baja cementerio. Al interior senderos que permiten el traslado vertical y horizontal. 


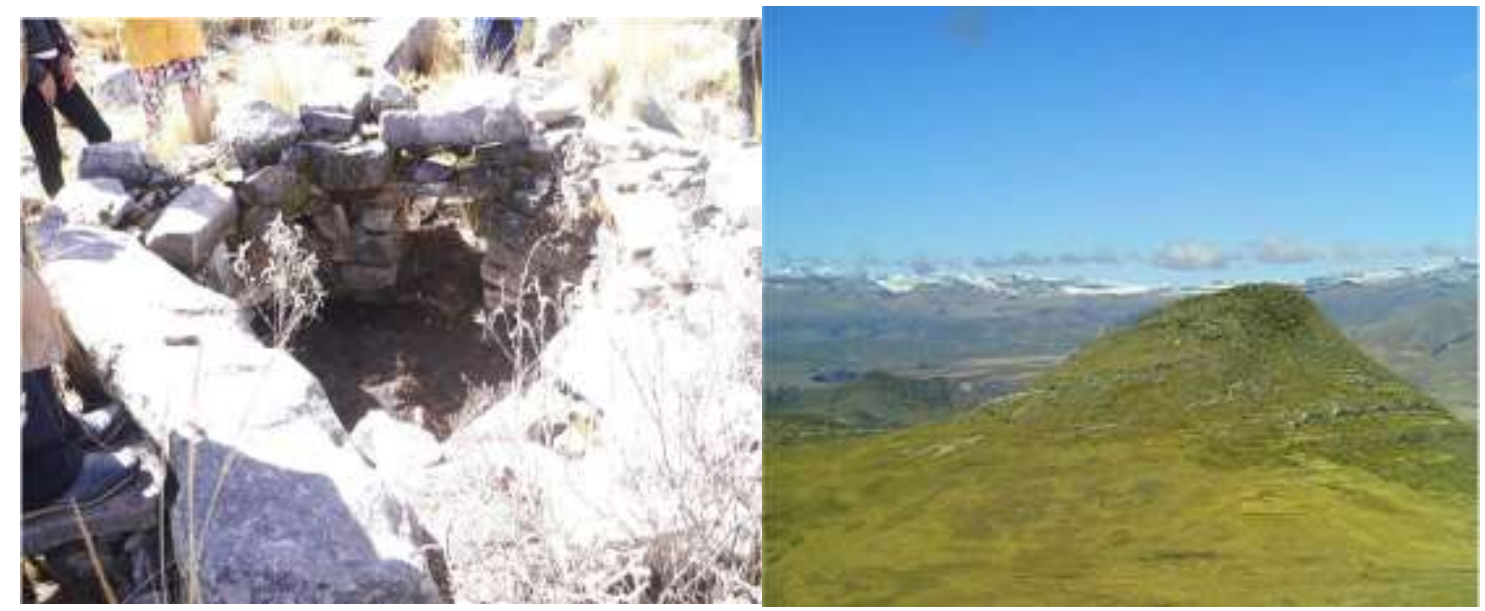

Fuente: Restos arqueológicos, construcciones en Auquimarca. 24.10.2019. Apu Puyca. Protegido por la Comunidad Campesina y distrito de Pomacocha. Centro ceremonial, con senderos que rodean la construcción, recintos o construcciones ovaladas con poca presencia de andenería, en cumbre plaza ceremonial.

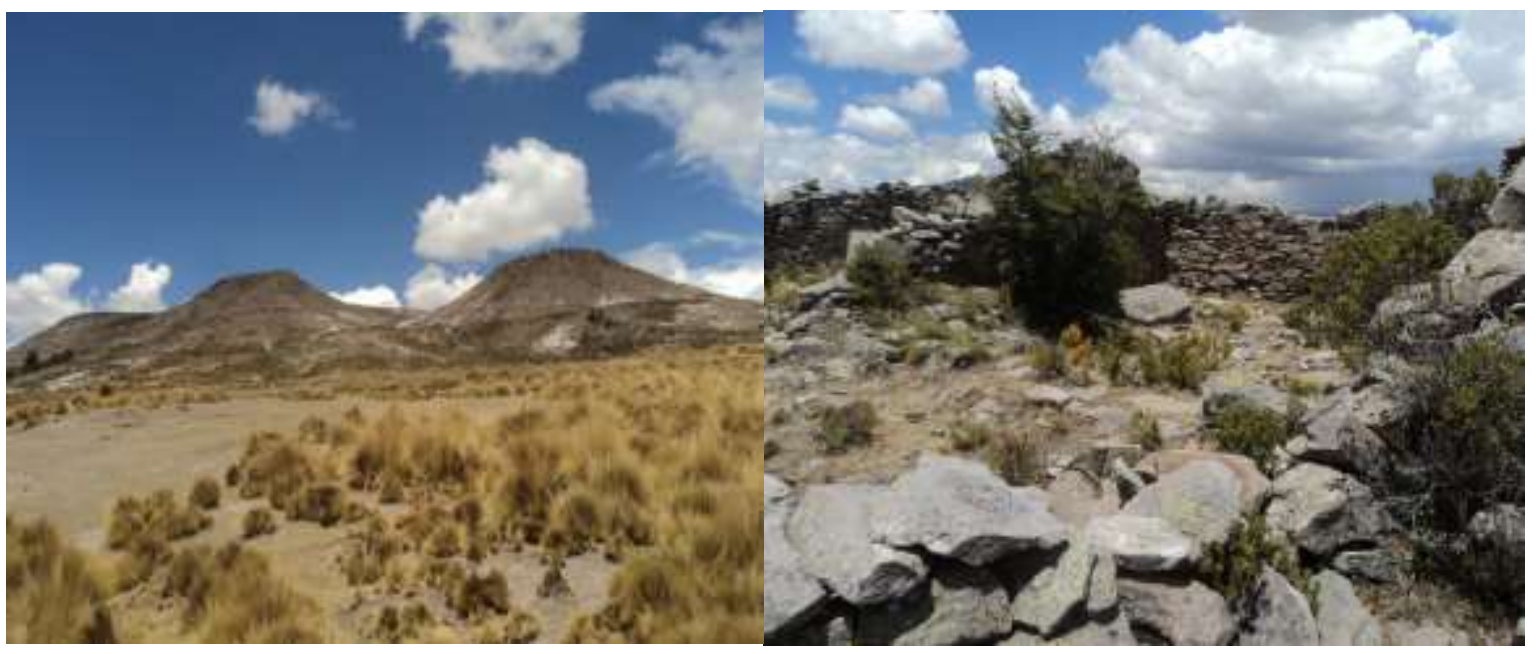

Fuente: Recurso arqueológico de Pabellones. 21.11.2019. Restos de construcciones no cuenta con ficha de inventario, abandonada su recuperación. Protegido por la Comunidad Campesina de Pampachiri. 

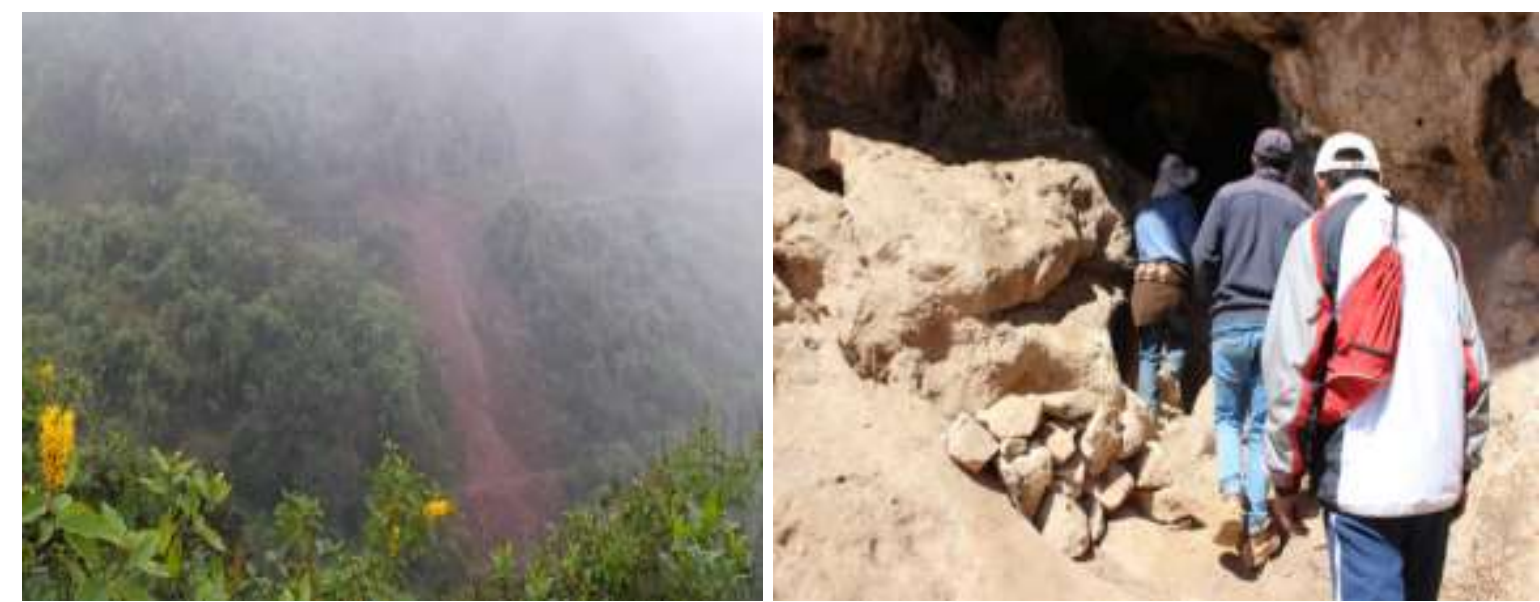

Fuente: Recurso eco turístico Bosque Uywari. 17.08.2019 a 35 minutos de la ciudad de soporte Andahuaylas, no cuenta con ficha de inventario, protegido por la Comunidad Campesina de Villla Esperanza Cotahuacho. Recurso arqueológico Cuevas de Toracca, 19.06.2019, contiene restos óseos humanos, figura lítica antropomórfica y centro ceremonial, abandonada su recuperación, no cuenta con ficha de inventario. Protegido por la Comunidad Campesina de Toracca.

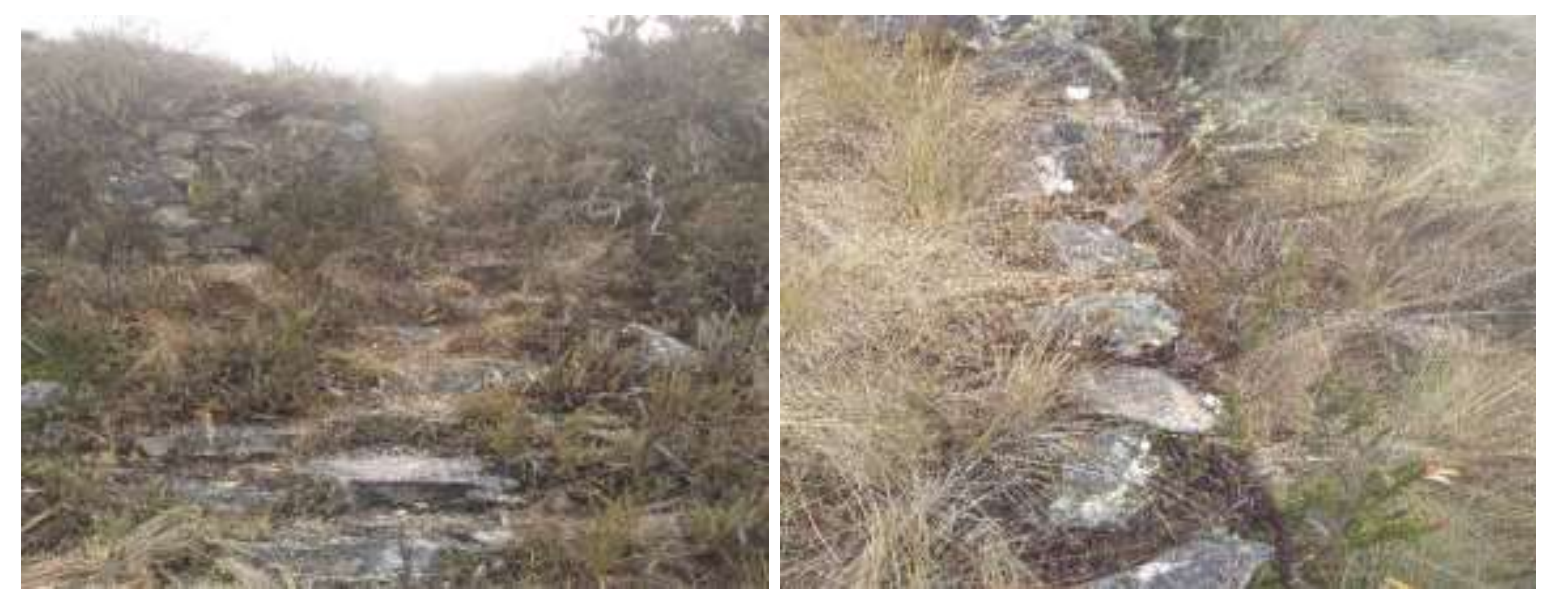

Recurso arqueológico Fortaleza de Llaqtapata, 19.10.2019, contiene restos de construcciones, en diversos niveles y usos, desde viviendas, plaza ceremonial, cuevas con restos óseos, abandonada su recuperación, no cuenta con ficha de inventario actualizada. Protegido por la Comunidad Campesina de Ccerabamba Andina y parcialidad de Pacchani, distrito de Pacobamba. 



Recurso arqueológico Fortaleza de Llaqtapata, 19.10.2019, contiene restos de construcciones, en diversos niveles y usos, desde viviendas, plaza ceremonial, cuevas con restos óseos, abandonada su recuperación, no cuenta con ficha de inventario actualizada. Protegido por la Comunidad Campesina de Ccerabamba Andina y parcialidad de Pacchani, distrito de Pacobamba. Bosque Chinchay, 10.11.2019, tipo montano húmedo y seco, con biodiversidad, 40especies de flora y 10 de fauna, permite avistamiento de animales, no cuenta con ficha de inventariado. Protegido por propietarios privados.


Recurso arqueológico de San José de Chontalla, comprende los sitios arqueológicos de Apu Qachinchilla, Apu Capay curo y Apu Chontalla, 14 y 15.07.2020, contiene restos de construcciones, en diversos niveles y usos, desde viviendas forma ovoide, plaza ceremonial con forma rectangular a circular, muros de contención pircados con piedra semi trabajada que suguen y adapta al relieve del terreno, existen restos de cerámica tratada a diferente ccoción, y destinadas a diversos usos. Abandonada su recuperación, no cuenta con ficha de inventario actualizada. Protegido por la Comunidad Campesina de 
Pampachiri, específicamente el anexo San José de Chontalla, distrito de Pampachiri. Permite avistamiento de aves y animales.

En Abancay, tenemos los siguientes recursos turísticos: Las ex haciendas cuyas construcciones están en condiciones de recuperación, restos arqueológicos en Tamburco, restos arqueológicos de Huanipaca, Complejo Arqueológico en Aymaraes, la ruta hacia el Complejo Arqueológico de Choccequirao desde el anexo de Cachora o Huanipaca, entre otros.

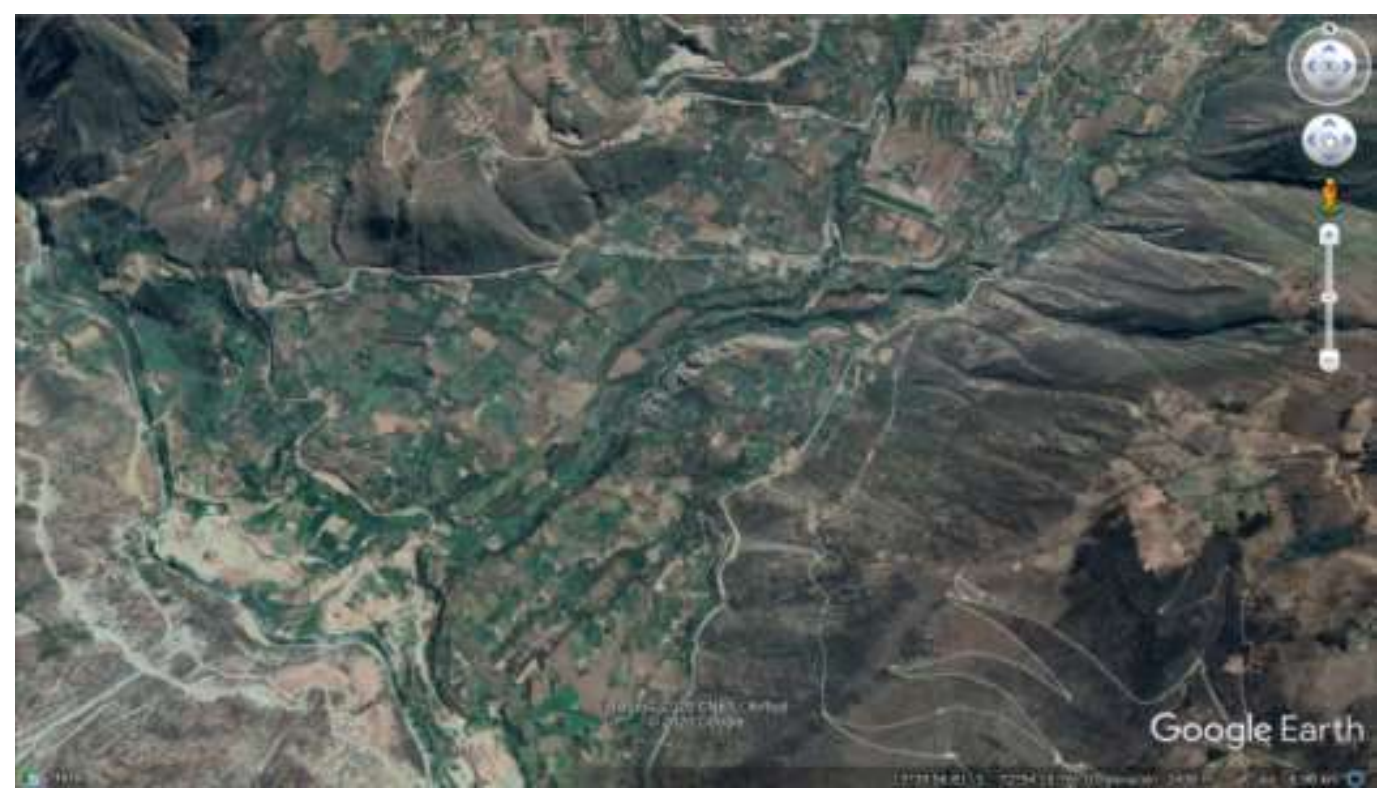

Fuente: Google Earth/ Image 2020 CNES/Airbus del 27 de mayo 2020. En dirección sur oeste de la planta de soporte de la ciudad de Abancay se ubican una considerable cantidad de Restos de las edificaciones de las Ex Haciendas, que están en situación de recuperación, están en un $70 \%$ a $80 \%$ completas las edificaciones; su aprovechamiento se podría realizar mediante el lanzamiento de una ruta turística de las Haciendas. La única reconstrucción de Hacienda recuperada a un $100 \%$ es Illanya, donde funciona la Dirección Desconcentrada del Ministerio de Cultura Apurímac. 


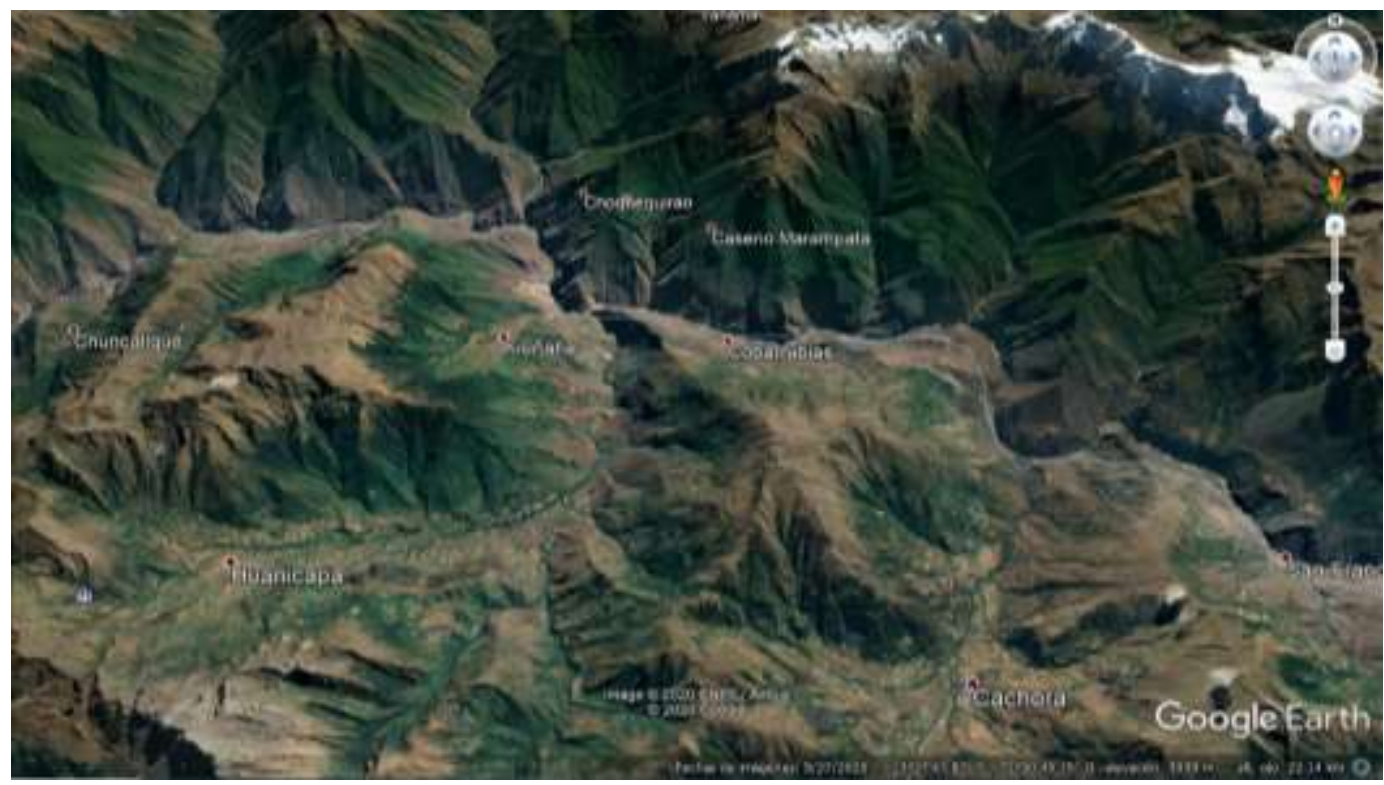

Fuente: Google Earth/ Image 2020 CNES/Airbus del 27 de mayo 2020. En dirección nor oeste saliendo desde la planta de soporte de la ciudad de Abancay, se ubica los poblados de Cachora y Huanipaca, los cuales son paso obligatorio hacia el Complejo Arqueológico de Choccequirao. Cada poblado presenta una ruta diferente, que luego se unen para el descanso en poblado al borde del río Apurímac, hacia Choccequirao, pasando por los caseríos de Santa Rosa y Marampata.

En la provincia de Chincheros, región Apurímac, tenemos un recurso arqueológico y eco turístico, además de uno vivencial-cultural, nos referimos al Complejo Arqueológico de Paccayranra, y el sector La Victoria. Mostraremos sobre algunos de ellos.

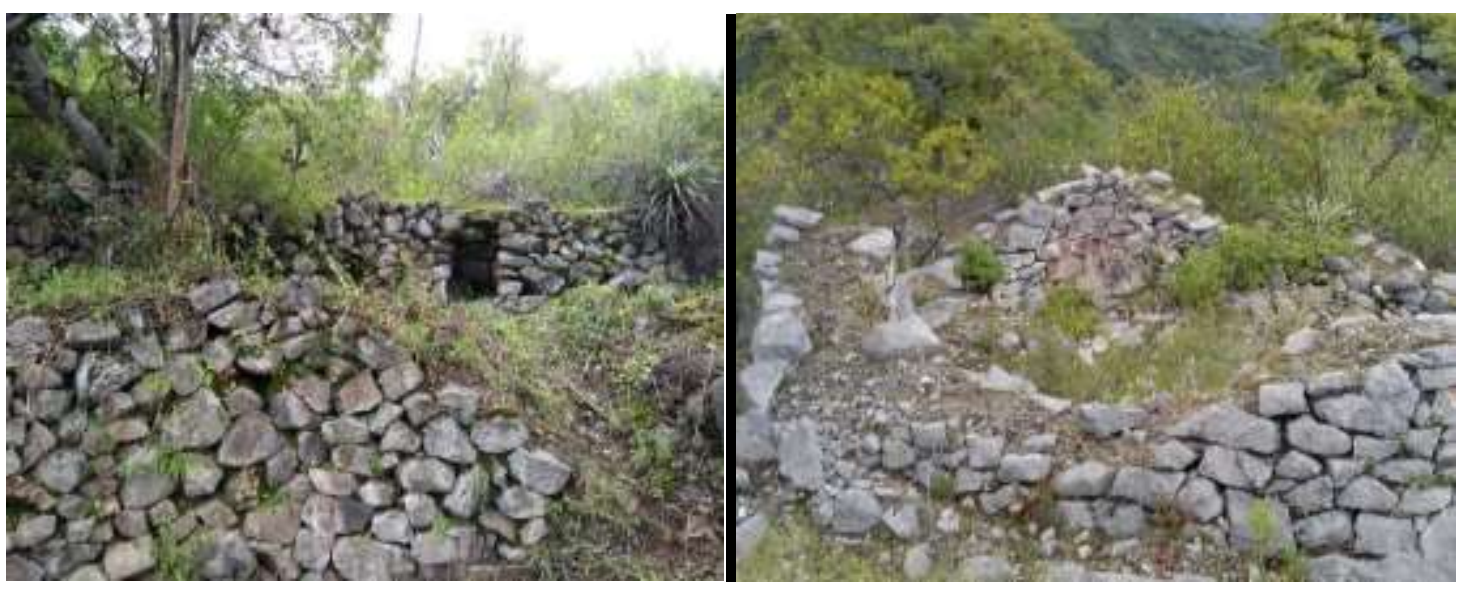

Recurso Complejo Arqueológico de Paccayranra, 19.06.2019, contiene restos de construcciones, en diversos niveles y usos, desde viviendas, plaza ceremonial, barreras 
de defensa de piedra calzada, rellenas, cuevas con restos óseos, en proceso su recuperación por el Ministerio de Cultura, cuenta con ficha de inventario en proceso de actualización. Protegido por la Comunidad Campesina de Cocharcas y parcialidad de La Victoria, distrito de Cocharcas.

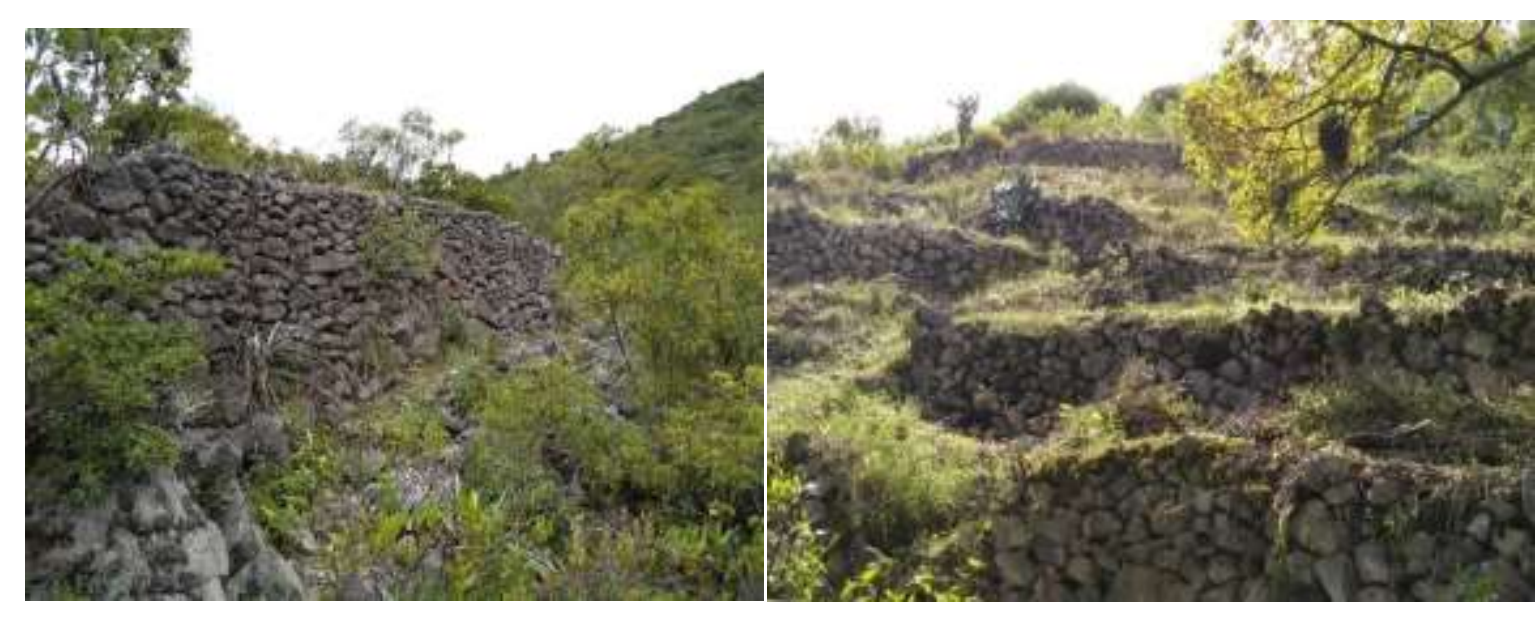

Recurso Complejo Arqueológico de Paccayranra, 19.06.2019, contiene restos de construcciones, en diversos niveles y usos, aquí observamos muros de contención que toman función de barreras de defensa de piedra calzada, rellenas, andenerías para adecuar el relieve del terreno para el uso agrícola, zanjas rectangulares revestidas con piedra para la función de reservorio de riego, en proceso su recuperación por el Ministerio de Cultura, cuenta con ficha de inventario en proceso de actualización. Protegido por la Comunidad Campesina de Cocharcas y parcialidad de La Victoria, distrito de Cocharcas. NO cuenta con administración el recurso turístico.

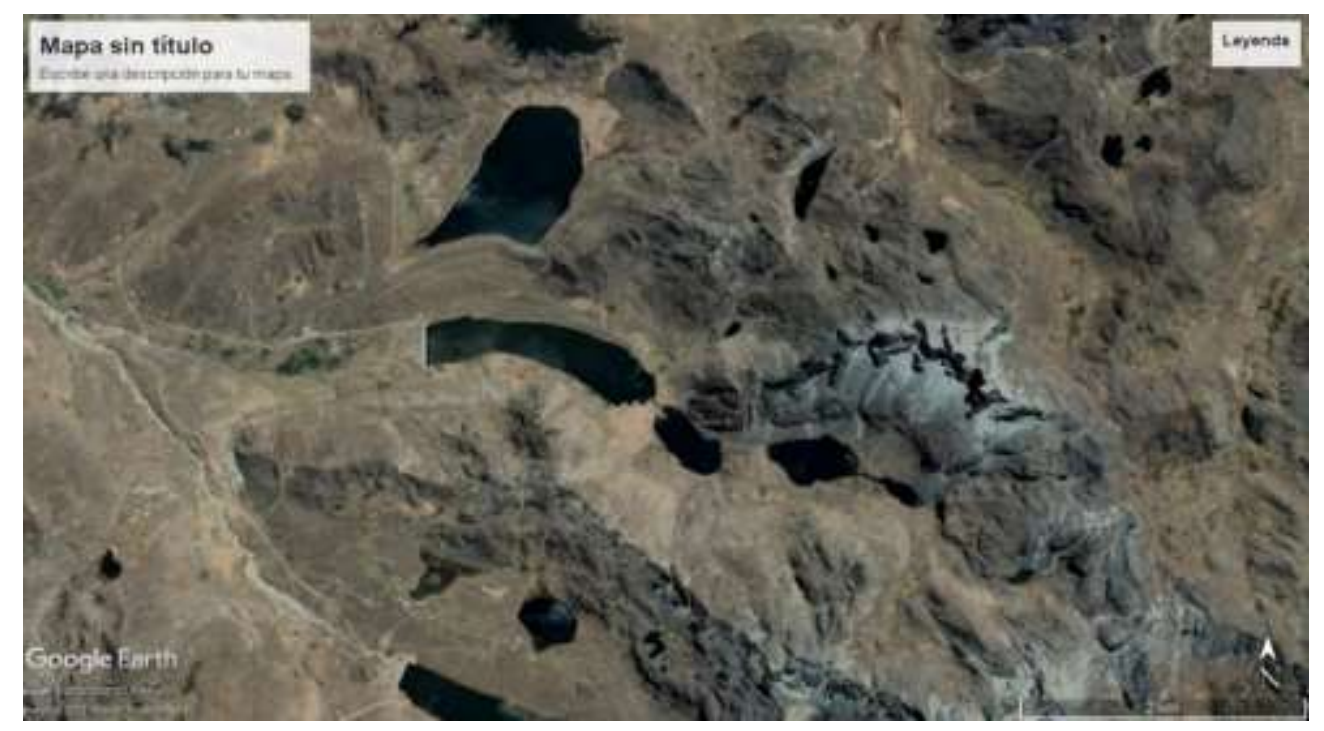

Ciencia Latina Revista Científica Multidisciplinar, Ciudad de México, México. ISSN 2707-2207 / ISSN 2707-2215 (en línea), julio-diciembre, 2020, Volumen 4, Número 2. https://doi.org/10.37811/cl rcm.v4i2.79 p. 315 
Fuente: Google Earth/ Image 2020 CNES/Airbus del 27 de mayo 2020. La toma satelital muestra la ruta eco turística "Ñan Orqupi ccocha Kunaman” formada por batería de lagos a desniveles ubicados a partir de los 4300 msnm, denominados: tipiccocha, carioccocha, paccoccocha, antaccocha; paisaje montano puna, especies de flora y fauna, se aprecia la montaña Qorawiri, forma de herradura, patrón de la provincia de Andahuaylas.

Los recursos mencionados, presentan una accesibilidad media, los trabajos de mantenimiento son realizados por consorcios ganadores de licitación pública, cuya mano de obra en su gran mayoría provienen de comuneros cercanos a la carretera secundaria. Además, existe mantenimiento de rutas secundarias internas, conocidas como trochas carrozables, cuya composición es de material afirmado en bi capa consistente. Todos los recursos turísticos por lo general se distancian cerca, a la carretera principal o secundaria. Al llegar al lugar se internan en el recurso turístico a través de un senderos en condiciones de mantenimiento regular, que permite conocer el recurso turístico. Desde las ciudades de soporte las distancias próximas se ubican entre un intervalo de 1 hora a 4 horas. Respecto a 1 seguridad y control administrativo, en los recursos turísticos, no presentan ningún avance en mejoras respecto a una caseta de ingreso-registro, instalaciones para protección de lluvia, descanso, además de servicios higiénicos, en el 95\% de los recursos turísticos, carecen de señalización. Para estos recursos turísticos, la categorización para alcanzar el status de destino turístico, atraviesa por momentos difíciles, lento trabajado burocrático, que descansa en la motivación de la presidencia regional de Apurímac, limitado presupuesto a la Dirección Regional de Comercio Exterior y Turismo, desinterés de stakeholders habituados a la presencia e inyección de inversión por parte del estado. La principal función de la Dirección Regional y sub Regionales de Turismo en Apurímac, es la promoción y difusión, que permitió fortalecer ciertos recursos convertidos en destino turístico, pero es muy difícil hasta el momento aprovecharlo por completo, muy a pesar de las limitaciones de oferta de servicios en la planta de soporte cercana al recurso turístico. 


\section{DISCUSIÓN}

Los antecedentes: Aguilar y Sáenz, Félix y García, Tumbaco, Grados y Morales, Ganchozo, nos indican que la metodología de investigación desarrollada se centró en recopilar, describir el potencial, de los diferentes tipos de recursos y atractivos turísticos, naturales, culturales, arqueológicos. Tomaron especial interés en aquellos recursos y atractivos que presentan condiciones respecto a los atributos que mantienen, poco deterioro, sumado a una frecuencia de visita que puede ser registrada, es decir aquellos que tienen una explotación de años considerables. A continuación, sustentamos las diferencias con los antecedentes:

No describen en forma específica otros recursos turísticos, que no tengan una inversión de implementación, una frecuencia de explotación considerable, por ello los estudios se ciñen a los recursos y atractivos ubicados cerca de la planta de soporte turístico. Asimismo, algunos se enfocan a describir, las condiciones actuales en que se encuentran los operadores turísticos, hasta proponer un plan de mejora, el cual solo contiene un programa de mercadeo o marketing para recuperar la imagen y posición del recurso o atractivo que tiene un desarrollo.

No intervienen explicando la propiedad donde se ubica el recurso, atractivo o destino turístico, porque sin el consentimiento del propietario u posesionario, no se puede iniciar ninguna intervención de mejora, por parte del sector público, además si el recurso o atractivo turístico no cuenta con saneamiento físico-legal, no se puede ejercer dominio completo por parte del estado e inclusive puede iniciarse reivindicaciones de propiedad sobre el recurso turístico, solo contempla una posesión que impide implementar mejoras. Asimismo, no toman mucha incidencia sobre las condiciones de accesibilidad externa, es decir hacia el recurso o atractivo turístico y accesibilidad interna que son los senderos al interior de recurso o atractivo turístico. Finalmente, solo dos de ellos contemplan un plan de mejora, pero no describen cómo se solucionarían problemas de acceso y formalización frente al trámite administrativo, tampoco consideran un posible diseño de nuevas rutas. Por ello se toma como referencia necesaria, no determinante las investigaciones hechas por Valle y otros, porque permite fortalecer lo que se pretende demostrar mediante las capacidades indicadas, además de preferir como técnica necesaria la captura satelital; proponer una forma de iniciar el aprovechamiento de los recursos turísticos; solo que, en 
esta oportunidad, nos ceñimos al enfoque cualitativo por la búsqueda, análisis de documentos y comparación con entrevistas a pobladores.

La investigación cuenta, además de la descripción detallada de cada recurso turístico, la ilustración, la ubicación, dominio del recurso y territorio comunal, las condiciones de accesibilidad; la propiedad del recurso turístico dentro del territorio comunal y su situación de saneamiento físico-legal, que permita el registro de propiedad completo y la forma en que se debería iniciar el aprovechamiento del recurso turístico, a pesar de las barreras de formalización para el recurso turístico y operadores turísticos. Debemos tener en cuenta que, si un recurso turístico no cuenta con inventario, es imposible iniciar el registro de identificación y protección, sumado a que si no cuenta con saneamiento físicolegal a la par con registros estadísticos de demanda, no puede iniciarse el aprovechamiento del mismo, por ello es que existe estas fuertes barreras, y el recurso turístico se va deteriorando con el tiempo o es explotado en forma irracional, desprotegido, como el caso del Bosque de piedras, Pankula en el distrito y comunidad de Pampachiri; el sitio arqueológico de Achanchicc en el distrito de Talavera y comunidad campesina de Uchuhuancaray; El Apu Timani en el distrito de kaquiabamba y parcialidad privada de Anyaniso, son una muestra de lo descrito respecto a las barreras.

Para iniciar una reactivación económica, lo primero que se tiene que hacer, es que un actor tome el liderazgo, en organizar a la comunidad campesina, el actor debe ser una institución a la que se respete, y ellos se identifiquen, caso la Universidad. En el territorio de la comunidad campesina, es donde se ubica el recurso turístico, el cual es protegido, conservado por la comunidad campesina, con el permiso y apoyo de la comunidad campesina se debe iniciar investigaciones sobre la potencialidad y características del recurso turístico, sumado a la capacitación de los comuneros, hasta la formación de una asociación de operadores turísticos, es determinante que se formalice una asociación de operadores turísticos de tal forma que permita la administración y mantenimiento del sitio arqueológico. Cuando se tenga la aprobación de la comunidad campesina de formalizar el recurso turístico de la mano con la municipalidad local, la formación de la asociación de operadores turísticos, el expediente de investigación completo y publicado, se derivan a la Oficina Descentralizada del Ministerio de Cultura Apurímac, para formulación de convenio y contrato de administración del sitio arqueológico. Igual procedimiento para la 
administración, se realiza, si el recurso turístico es natural, corresponde a la Dirección Regional de Comercio Exterior y Turismo Apurímac, con visto bueno del Servicio Nacional de Conservación de Áreas Naturales Protegidas (SERNARP) o Autoridad Local del Agua (ALA), la autorización del aprovechamiento para las zonas como: bosque, catarata, montaña, desfiladero, entre otros. Es necesario, que se llegue a aprovechar los recursos turísticos, porque son una salida a la difícil situación económica-social por la que atraviesan las poblaciones de las comunidades campesinas, la flexibilización del proceso de saneamiento físico-legal y administrativos para consolidar el aprovechamiento del recurso turístico, el cual cuenta con la predisposición de la comunidad campesina para la administración y mantenimiento. Además, un actor clave es la Municipalidad local, quién debe aprobar la zona donde se ubica el recurso ecoturístico, declararla como: "Zona de aprovechamiento y patrimonio cultural" antes de iniciar el proceso las instancias regionales como Oficina Descentralizada del Ministerio de Cultura Apurímac o la Dirección Regional de Comercio Exterior y Turismo Apurímac o La Dirección Descentralizada del Servicio Nacional de Conservación de Áreas Naturales Protegidas Apurímac.

Po tal motivo, la modalidad turística que se puede iniciar sin inversión fuerte, tomando lo que existe en el recurso turístico, sin construir infraestructura fija, por el contrario, afianzar limpieza de senderos, ubicar tachos para desechos sólidos, algunos carteles de señalización, es: el Ecoturismo, en las actividades de hikking, trekking, acampar, andinismo, paisajismo, visita a sitios arqueológicos que se complementan con acampar y caminar por el inca ñan o camino inca; porque el potencial de los recursos turísticos, basados en sus atributos que existen, fortalecen, posicionan directamente, el aprovechamiento en estas cuatro actividades turísticas. Las acciones de aprovechamiento del recurso turístico se realizan bajo requisitos mínimos que se debe cumplir en la orientación turística de grupos pequeños, es decir no mayores entre 6 a 7 personas, siendo un servicio exclusivo, personalizado, además de los protocolos de seguridad, distanciamiento social. Siendo la comunidad campesina, que protege, conserva el recurso turístico, quién organizó la asociación de operadores turísticos, es la primera, directa en prestar los servicios de la administración del recurso turístico, los cuales puede complementar con servicios como: guiaje interno, alimentación, danzas, rituales. El ecoturismo es la modalidad de turismo alternativo, que permitirá el despegue de otras 
actividades turísticas como: alpinismo, parapente, globo aerostático, porque las condiciones geográficas y vientos se presta para ofrecer las actividades turísticas en segunda etapa.

\section{CONCLUSIÓN}

Las tres provincias de la región Apurímac: Abancay, Andahuaylas, Chincheros, cuentan con un potencial de recursos turísticos únicos, incomparables. Los mismos se han preservado debido a las condiciones geográficas, accesibilidad restringida, cuidado de la comunidad campesina. Los recursos turísticos, una considerable cantidad cuenta con ficha de inventario y el registro respectivo, pero falta actualizarlo, porque los datos contenidos en la ficha son de los años 70 a 90 del siglo XX, el saneamiento físico-legal no existe en los recursos turísticos, lo mismo para aquellos recursos turísticos en aprovechamiento y administración por la comunidad campesina. Las barreras para iniciar aprovechamiento de un recurso turístico, se ciñen a:

1. Existencia de ficha de inventario,

2. Proceso y registro público del saneamiento físico-legal,

3. La estadística de frecuencia de visitas o demanda de turistas,

4. Operadores turísticos formalizados,

5. Dependiendo el tipo de recurso, están en función directa y normativa con: Ministerio de Cultura o Vice Ministerio de Turismo o Servicio Nacional de Conservación de Áreas Naturales Protegidas.

6. La predisposición política del alcalde de la municipalidad de la jurisdicción en promulgar mediante ordenanza municipal, como área de aprovechamiento y patrimonio cultural, donde se ubican los recursos turísticos; naturales, arqueológicos, culturales, históricos.

La recuperación económica en el sector turismo, se puede iniciar sin inversión fuerte, tomando lo que existe en el recurso, sin construir infraestructura fija, por el contrario, se prioriza acciones como: afianzar limpieza de senderos, ubicar tachos para desechos sólidos, algunos carteles de señalización, nos referimos al: Ecoturismo, las actividades turísticas conexas adecuadas para este tipo de turismo son: hikking, 
trekking, acampar, andinismo, paisajismo, visita a sitios arqueológicos que se complementan con acampar y caminar por el inca ñan o camino inca; dado que los atributos que existen, fortalecen, posicionan directamente, el aprovechamiento del recurso turístico a partir de estas cuatro actividades turísticas. El aprovechamiento, se realiza bajo requisitos mínimos que se debe cumplir en la orientación turística de grupos pequeños, es decir no mayores entre 6 a 7 personas, siendo un servicio exclusivo, personalizado, además de los protocolos de seguridad, distanciamiento social. La comunidad campesina, será la encargada de la administración del recurso turístico, los cuales puede complementar con servicios como: guiaje interno, alimentación, danzas, rituales. El ecoturismo es la modalidad de turismo alternativo, que permitirá el despegue de otras actividades turísticas como: alpinismo, parapente, globo aerostático, porque las condiciones geográficas y vientos se presta para ofrecer las actividades turísticas en segunda etapa.

\section{Lista de referencias}

Aguilar, L., \& Sáenz, P. (2019). Circuito turístico en el municipio de Mariquita a partir de sus recursos culturales e históricos. Bogotá, Colombia: Universidad Agustiniana.

Chancos, J. (2019). Conceptos geo ambientales en el marco de la geografía contemporánea. Lima.

Félix, Á., \& García, N. (2020). Estudio de pérdidas y estrategias de reactivación para el sector turístico por crisis sanitaria COVID 19 en el destino Manta. Revista Internacional de Turismo, Empresa y Territorio, 79-103.

Ganchozo, G. (2018). Análisis del potencial turístico caso Piñas El oro. Machala: Universidad Técnica de Machala.

Gonzales, J., \& Huanca, K. (2018). Impacto de la actividad turística en el crecimiento de la economía regional de Cusco, 2000-2015. Cusco, Cusco, Perú: Universidad Andina del Cusco.

Graglia, G. (junio de 2020). Contexto Turismo y Covid 19. Programa comercial Express de la Ruta de la Competitividad Turística. Lima, Lima, Perú: Promperú. 
Granados, C., \& Morales, G. (2019). Análisis del potencial turístico del Cantón de Paraíso . cartago: Instituto Tecnológico de Costa Rica.

Hernández, R., Fernández, L., \& Baptista, P. (2014). Metodología de la investigación. México, México: Mc Graw Hill.

Marín, H. (Febrero de 2012). Recursos turísticos. Introducción a los recursos turísticos. Murcia, España.

Rural, P. E. (1999). Directorio de comunidades campesinas. Lima: R \& R Publicistas asociados.

Tumbaco, B. (2019). Atractivos turpisticos del cantón Mocache y su incidencia en el desarrollo económico. Babahoyo, Entre ríos, Ecuador: Universidad Técnica de Babahoyo.

Turismo, O. M. (Abril de 2020). Evaluación del impacto del brote de Covid 19 en el turismo internacional. Estados Unidos de Norteamérica: Organización Mundial de Turismo.

Turismo, O. M. (Mayo de 2020). Programa de asistencia técnica para la recuperación del turismo de la crisis de la Covid 19. Estados Unidos: Organización Mundial de Turismo.

Turismo, V. m. (Diciembre de 2018). Guía para la actualización e inventario de recursos turísticos. Lima, Lima, Perú: Ministerio de Comercio Exterior y Turismo Perú.

Turismo-Artesanía, D. G. (2019). Perú: Compendio de cifras de Turismo 2019. Lima, Lima, Perú: Vice minsiterio de Turismo.

Valle Díaz, F. R. (2019). Bienestar colectivo comunal a nivel de microcuencas en comunidades campesinas, provincia de Andahuaylas, región Apurímac. La vida y la Historia, 85-95.

Valle, F., Delgado, M., Huanca, J., Mendez, R., Solano, T., \& Barrial, A. (2020). Inventario y aprovechamiento de la ruta ecoturística Nan Orqupi Sachas 
Chinchay, distrito Pacobamba, Apurímac, Perú. American Journal of Humanities and Social Science, 11.

Valle, F., Huamán, Y., \& Salas, L. (2019). Propuesta de inversión para explotación de zona ecoturística, Andahuaylas, Apurímac, Perú-2018. En I. N. Continua, Libro de resúmenes del II Congreso Latinoamericano de Investigación y Posgrado. Lima: DELECTUS.

Valle, F., Salazar, Y., \& Ripa, I. (2020). Aprovechamiento de la zona ecoturística Orccopi Kunaman Suitoccocha, distrito José María Arguedas, Apurímac, Perú. Revista científica Ciencia, tecnología y sociedad de la Universidad José María Arguedas, 10. 